\title{
PENGKLONAN DAN PERUNUTAN NUKLEOTIDA GEN SELUBUNG PROTEIN DAN 3'UTR (untranslated region) PEANUT STRIPE VIRUS
}

\author{
Hasriadi Mat Akin ${ }^{1}$
}

\begin{abstract}
ABAST ACT
Cloning and sequencing of coat protein gene and 3'UTR (untranslated region) of peanut stripe virus. The CDNA of 3' terminal of peanut stripe virus genomic RNA was cloned and sequenced. The cDNA was ligated with plasmid vector pGEM-T Easy and transformed to competent cells of Escherichia coli. The 3' terminal of PstV genomic RNA contained 1195 nucleotides (nts). The region included the nucleotide sequences of NIb (nuclear inclusion body) (129 nts), CP gene (coat protein gene) (861 nts), and 3'UTR (untranslated region) (205 nts). The nucleotide sequence of a CP gene contained one long uninterrupted open reading frame (ORF) without a start codon, which ended a UAG stop codon. The 287 amino acid residues of PStV coat protein were predicted from the CP gene. The amino acid was analyzed for the presence of consensus polyprotein cleavage site for maturation of potyvirus polyprotein. A putative cleavage site was found at position $43(\mathrm{Q} / \mathrm{S})$ following the Valine $(\mathrm{V})$ residue at -4 position. This isolate of PstV can be expected to be aphid transmissible because the coat protein contained a DAG triplet at position 53-55.
\end{abstract}

Kata Kunci: Peanut Stripe Virus, pengklonan dan perunutan nukleotida, gen selubung protein PStV

\section{PENDAHULUAN}

PStV adalah salah satu spesies dari genus Potyvirus, dan famili Potyviridae (Francki et al., 1991). Potyvirus paling banyak menimbulkan kerugian hasil pertanian dibandingkan dengan virusvirus dari genus yang lainnya. Hal ini disebabkan oleh jumlah spesies potyvirus yang banyak, penyebaran yang mudah melalui kutu daun secara nonpersisten yang sulit dikendalikan, infeksinya pada tanaman inang yang menimbulkan gejala nekrosis, klorosis, dan kerdil (Lindbo et al., 1992; Tomaru, 1994). Hasil penelitian Akin dan Sudarsono (1997) menunjukkan adanya enam strain PStV dari PStV yang diisolasi dari berbagai daerah di Indonesia. Strain-strain PStV tersebut dibedakan berdasarkan karakter gejala infeksinya pada kacang tanah kultivar Landak, yaitu: blotch, blotch-stripe, chlorotic ring-mottle, mild mottle, severe blotch-stripe, dan stripe.

Genom PStV terdiri atas 10059 nt tidak termasuk poliadenilat (poli-A) pada ujung 3' RNAPStV. Pada ujung ujung 5' genom PStV terdapat protein (VPg) yang terikat secara kovalen pada RNA (Gunashinghe et al., 1994; Shaw et al., 1990). Genom RNA tersebut terdiri atas satu kerangka baca (open reading frame) yang meliputi $95 \%$ genom $\mathrm{PStV}$.
Kodon awal terletak 134-136 dan kodon akhir terletak pada posisi 9768-9770 nukleotida dari ujung bagian 5’ RNA (Gunashinghe et al., 1994).

Taksonomi potyvirus, sebagai kelompok virus tumbuhan terbesar, sampai saat ini masih sulit dilakukan dengan baik karena besarnya variasi diantara anggota kelompok sehingga sulit membedakan antar strain potyvirus (Ward \& Shukla, 1990). Shukla dan Ward (1988) menggunakan runutan asam amino CP untuk menilai hubungan kekerabatan dari 17 strain yang berasal dari delapan spesies potyvirus. Hasil kajian tersebut menunjukkan spesies-spesies yang berbeda mempunyai kesamaan runutan asam amino CP 38-71\% dan untuk strainstrain dalam virus yang sama homologinya 90-99\%. Frankel et al. (1989) melaporkan hasil studi homologi runutan nukleotida 3'UTR strain-strain dari watermelon mosaic virus (WMV) dan soybean mosaic virus (SMV). Hasil studi tersebut menunjukkan homologi runutan nukleotida 39-53\% untuk virus yang berbeda dan 83-99\% untuk strain dalam jenis virus yang sama.

Penelitian ini bertujuan untuk mengklon (clone) dan merunut (sequence) nukleotida bagian 3' dari genom PStV sebagai langkah awal untuk mengembangkan metode deteksi PStV dan rekayasa

\footnotetext{
${ }^{1}$ Dosen Jurusan Proteksi Tanaman, Fakultas Pertanian, Universitas Lampung
} 
genetika tanaman kacang tanah tahan PStV. Dalam tulisan ini akan dilaporkan runutan nukleotida gen CP (coat protein), sebagian sistron NIb (nuclear inclusion body), dan 3'UTR (untranslated region) dari genom PStV.

\section{BAHAN DAN METODE}

\section{Ekstraksi Total RNA dari Daun Kacang Tanah}

Ekstraksi total RNA dari daun kacang tanah dilakukan mengikuti prosedur yang dikemukakan oleh Thomson dan Dietzgen (1995). Daun kacang tanah (0,5 gr) digerus dalam $500 \mu$ l larutan A (dapar 0,5 M kalium fosfat $\left.\mathrm{pH} \quad 8,3 ; 0,5 \% \quad \mathrm{Na}_{2} \mathrm{SO}_{3}\right)$ dan disentrifugasi $12.000 \mathrm{rpm}$ selama 5 menit. Supernatannya diambil dan larutan A ditambahkan lagi sampai volumenya menjadi $500 \mu \mathrm{l}$ dan kemudian ditambahkan $500 \mu$ larutan B (0,1M NaCl, 2\% Triton $\mathrm{X}-100,4 \%$ PEG 6000) dan diinkubasi selama 1 jam pada suhu $4^{\circ} \mathrm{C}$. Larutan tersebut kemudian disentrifugasi $12.000 \mathrm{rpm}$ selama 10 menit, endapannya dilarutkan dalam $10 \mu \mathrm{l} 1 \mathrm{x}$ TE $(10 \mathrm{mM}$ Tris-HCl pH 8,0, $2 \mathrm{ml}, 1 \mathrm{mM}$ EDTA $\mathrm{pH} 8,0)$ dan disimpan pada suhu $-20^{\circ} \mathrm{C}$.

\section{Amplifikasi cDNA Gen CP dan 3'UTR}

Amplifikasi cDNA dari RNA-PStV yang meliputi sebagian gen $\mathrm{NIb}$, gen $\mathrm{CP}$, dan 3'UTR dilakukan dengan teknik RT-PCR (reverse transcription and polymerase chain reaction) mengikuti prosedur Titan One Tube RT-PCR Kit (Boehringer Mannheim). Primer oligonukleotida yang digunakan adalah PST1 (5'GCATGCCCTCGCCATTGCAA3') yang komplementer dengan basa ke 10.003-9984 pada bagian 3'UTR dan PST4 (5'TACATAGCAGAATCAGCACT3') yang homolog dengan nukleotida 8810-8829 pada sistron NIb. Hasil amplifikasi diamati dengan elektroforesis gel $1 \%$ agarose/1xTAE (50x TAE terdiriatas 2M Tris$\mathrm{HCl}, \mathrm{pH} 8,3 ; 0,99 \mathrm{M}$ asam asetat pekat, dan 50mM EDTA). cDNA 1,2 Kb hasil amplifikasi RT-PCR dimurnikan menggunakan QIAprep spin Kit (QIAGEN).

\section{Pengklonan cDNA Gen CP dan 3'UTR}

cDNA gen CP dan 3'UTR diligasi dengan plasmid vektor pGEM-T Easy (Promega). Plasmid rekombinan ditransformasi ke Escherichia coli $\mathrm{DH} 5 \alpha$ (Max Efficiency/ Life Technologies). Selanjutnya E. coli dikulturkan pada media seleksi LB yang mengandung ampisilin $(100 \mu \mathrm{g} / \mathrm{l})$, X-gal $(0,8 \mathrm{mg} / \mathrm{l})$, dan IPTG $(0,8 \mathrm{mg} / \mathrm{l})$. Klon rekombinan diidentifikasi dengan teknik PCR menggunakan primer SP6 dan T7 mengikuti prosedur yang telah dikembangkan oleh Thomson (1997).

Plasmid pGEM-T Easy merupakan plasmid high copy number dan mempunyai penanda seleksi ampisilin. Situs kloning terletak pada lazZ sehingga klon rekombinan dapat diketahui berdasarkan warna koloni. Koloni berwarna putih mengidikasikan bahwa bakteri tersebut mengandung plasmid rekombinan karena terjadi inaktivasi lacZ karena penyisipan DNA pada lacZ.

Plasmid rekombinan diisolasi mengikuti prosedur QIAprep spin miniprep Kit (QIAGEN). Untuk mengetahui ukuran DNA yang disisipkan pada plasmid vektor dilakukan analisis enzim restriksi (EcoR1). Pemotongan dengan EcoR1 akan menghasilkan dua fragmen DNA, yaitu: $3 \mathrm{~Kb}$ yang berasal dari plasmid vektor dan $1,2 \mathrm{~Kb}$ yang berasal dari sisipan DNA. Plasmid rekombinan yang telah dimurnikan digunakan untuk perunutan nukleotida DNA 3’ genom RNA-PStV.

\section{Perunutan Nukleotida cDNA Gen CP dan 3'UTR}

Perunutan nukleotida gen CP dan 3' UTR dari plasmid rekombinan dilakukan mengikuti prosedur BigDye Terminator Kit (Perkin Elmer). Primer T7 dan SP6 dan empat primer internal digunakan untuk mengetahui total runutan nukleotida kedua utas cDNA 3' genom RNA-PStV (Tabel 1). Runutan nukleotida dibaca dengan bantuan alat ABI PRISM Model 377 Version 3.0. Konsensus runutan nukleotida untuk masing-masing strain ditentukan berdasarkan runutan nukleotida dari dua klon dan apabila terdapat perbedaan nukleotida dari kedua klon tersebut maka klon ketiga digunakan untuk menentukan nukleotida pada posisi tersebut. 
Tabel 1. Primer yang digunakan untuk amplifikasi dan perunutan nukleotida cDNA dari 3’ genom RNA-PStV

\begin{tabular}{lll}
\hline Primer & Runutan nukleotida & Posisi hibridisasi \\
\hline PST5 & 5-'GCCTTTCAGTATTCTCGCTG-3' & $9740-9721$ \\
PST7 & 5'-CAATTGACATCTGTTCATC-3' & $9326-9308$ \\
PST8 & 5'-CTTCGTCAAATCATGCACC-3' & $9461-9479$ \\
PST10 & 5'-AATGAATGATGAACAGATGTC-3' & 9301-9321 \\
\hline
\end{tabular}

HASIL DAN PEMBAHASAN

\section{Amplifikasi cDNA Gen CP dan 3'UTR}

Hasil amplifikasi RT-PCR menggunakan primer PST1 dan PST4 diperoleh cDNA berukuran
1,2 Kb (Gambar 1). DNA tersebut merupakan hasil amplifikasi sebagian sistron NIb, CP, dan 3'UTR. Sebagai kontrol juga dilakukan amplifikasi cDNA 234 bp menggunakan primer spesifik untuk deteksi PStV yang telah dikebangkan oleh Akin (1998).

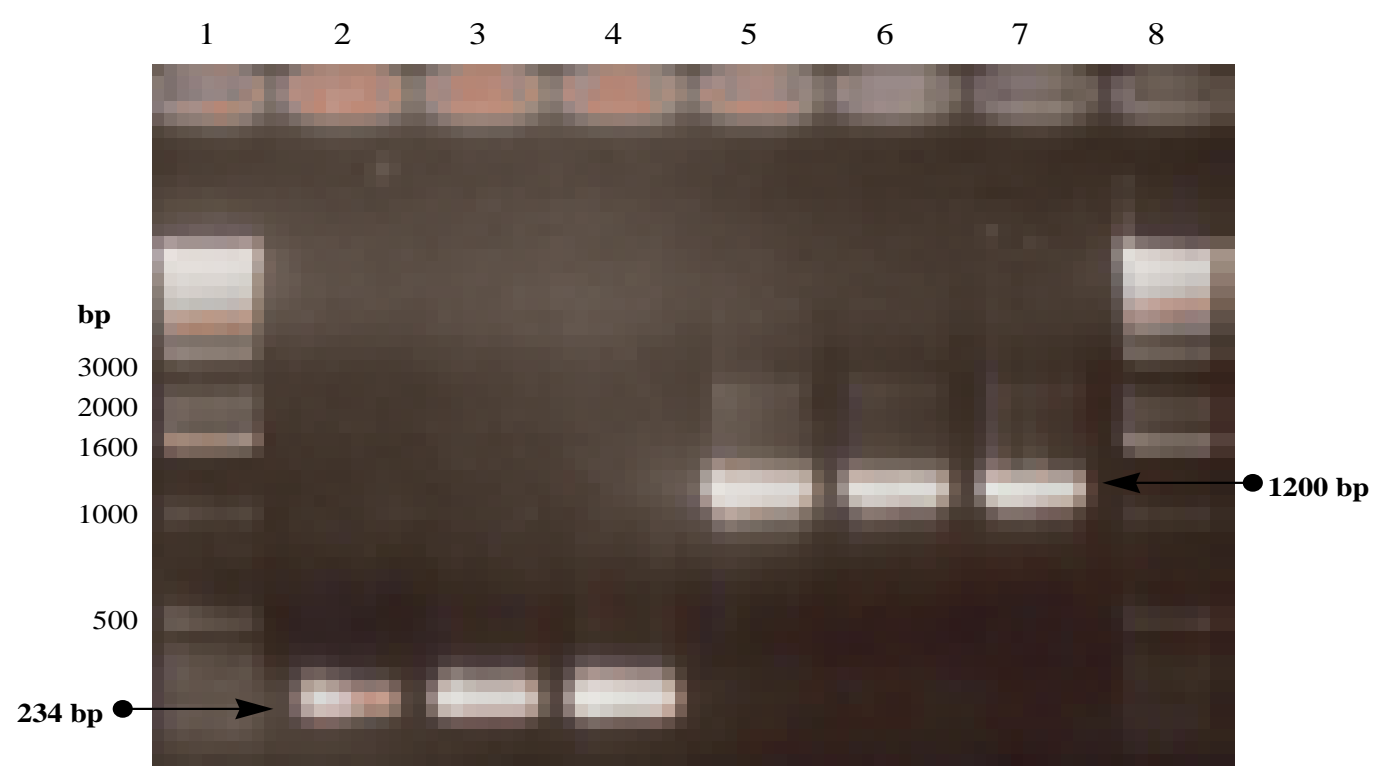

Gambar 1. Hasil amplifikasi RT-PCR cDNA dari genom RNA-PStV. Lajur 1 dan 8: 1 Kb marker; 2,3,4: hasil amplifikasi cDNA (234 bp) menggunakan primer PST1 dan PST2; 5,6,7: hasil amplifikasi cDNA (1200 bp) menggunakan primer PST1 dan PST4.

\section{Pengklonan cDNA Gen CP dan 3’UTR}

Hasil amplifikasi RT-PCR (cDNA 1,2 Kb) dari genom RNA-PStV diligasi dengan plasmid vektor (pGEM-T Easy) dan ditransformasi ke E. coli DH5 $\alpha$. Analisis plasmid rekombinan menggunakan enzim endonuklease (EcoR1) menghasilkan dua fragmen
DNA yang masing-masing berukuran $3 \mathrm{~Kb}$ dan 1.2 $\mathrm{Kb}$ (Gambar 2). Hasil seleksi klon rekombinan tersebut menunjukkan bahwa antara plasmid vektor pGEM-T (3 Kb) dan cDNA (1.2 Kb) sudah membentuk plasmid rekombinan yang berukuran 4.2 $\mathrm{Kb}$. 


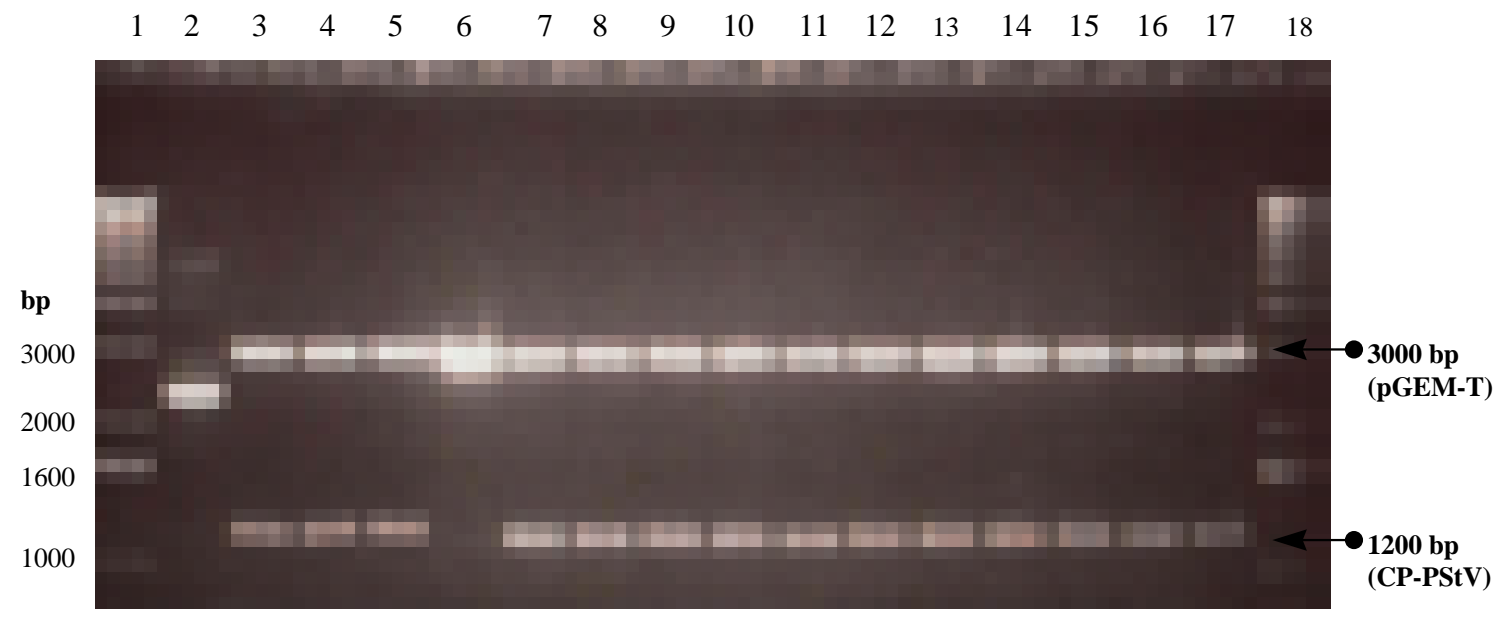

Gambar 2. Hasil pemotongan plasmid rekombinan dengan EcoR1.

Lajur 1dan 18: $1 \mathrm{~Kb}$ marker; 2: plasmid rekombinan; 6: plasmid vektor (pGEM-T) yang tidak mengandung gen CP-PStV; 3-17: plasmid rekombinan yang dipotong dengan EcoR1.

Perunutan Nukleotida cDNA Gen CP dan 3'UTR Runutan nukleotida RNA pada bagian 3' genom RNA-PStV terdiri atas 1195 nt (Gambar 3). Runutan nukleotida tersebut merupakan 129 nt sistron NIb, 861 nt gen CP, dan 205 nt 3’UTR. Gen CP PStV mempunyai satu kerangka baca (open reading frame) tanpa kodon awal dan diakhiri dengan kodon stop pada yang memisahkan CP dengan 3'UTR.

Prediksi runutan asam amino CP dari runutan nukleotida gen CP menghasilkan 287 asam amino.
Terdapat situs pemotongan protease $(\mathrm{Q} / \mathrm{S}$ : glutamin/serin) yang memisahkan runutan asam amino CP dengan NIb, dan pada posisi -4 bagian hulu $\mathrm{Q} / \mathrm{S}$ terdapat valin $(\mathrm{V})$ yang merupakan runutan asam amino yang diperlukan dalam proses pemotongan poliprotein hasil translasi genom potyvirus. Runutan asam amino CP PStV mempunyai motif DAG (asam aspartat-alanin-glisin) sebagai situs pengenal dalam proses transmisi dengan vektor aphid. 


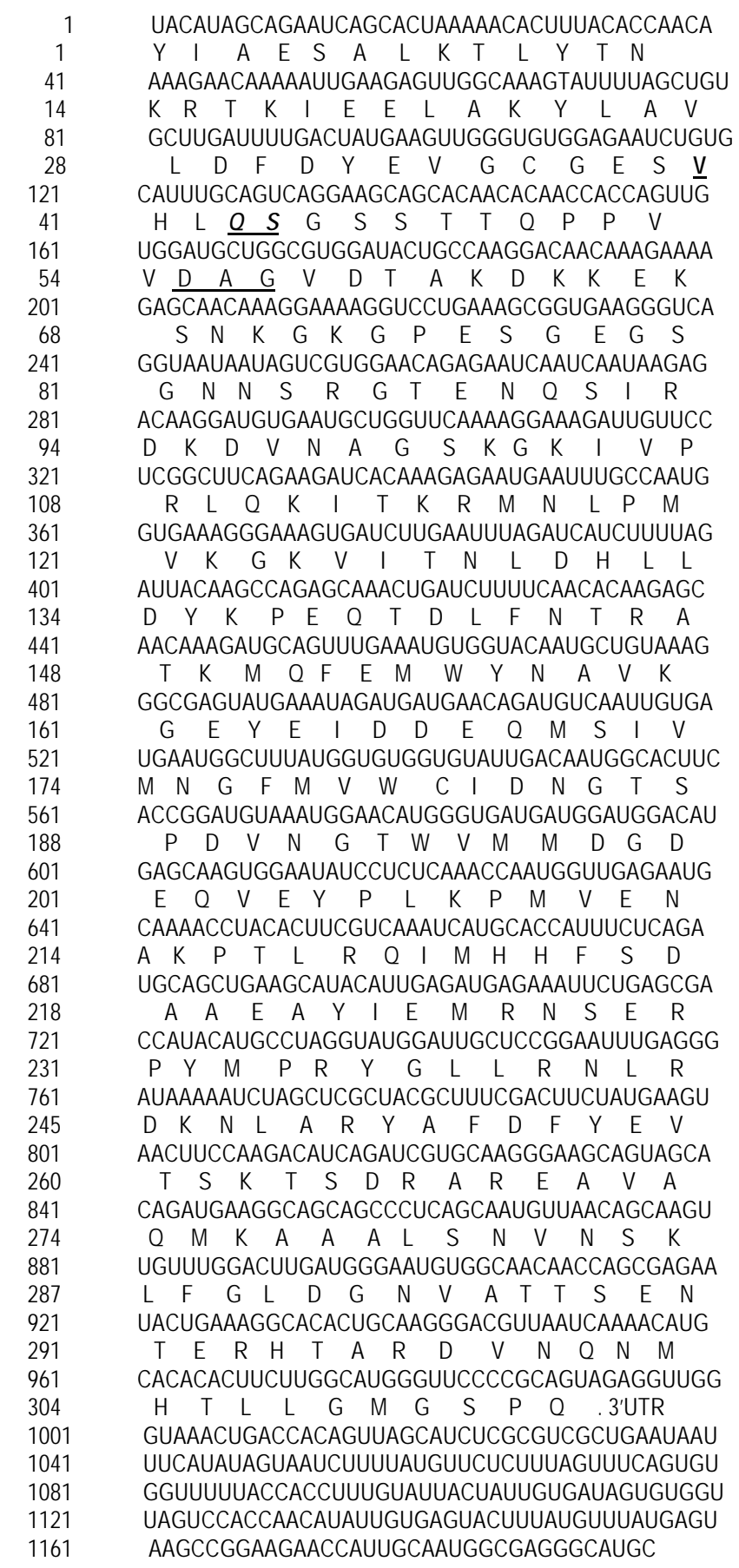

Gambar 3. Urutan nukleotida gen CP dan 3’UTR dari PStV dan prediksi urutan asam amino protein selubung PStV.

\section{KESIMPULAN}

1. Hasil amplifikasi cDNA dari 3' genom RNAPStV yang meliputi sebagian NIb, gen CP-PStV, dan 3'UTR telah diklon pada plasmid vektor (pGEM-T Easy) dan ditransformasi ke E. coli DH5 $\alpha$. 
2. Runutan nukleotida RNA pada bagian 3' genom RNA-PStV terdiri atas 1195 nt. Runutan nukleotida tersebut merupakan 129 nt sistron NIb, 861 nt gen CP, dan 205 nt 3'UTR.

3. Prediksi runutan asam amino $\mathrm{CP}$ dari runutan nukleotida gen CP menghasilkan 287 asam amino.

\section{UCAPAN TERIMA KASIH}

Penulis mengucapkan terima kasih dan penghargaan yang sebesar-besarnya kepada Proyer URGE (University Reseach for Graduate Education) melalui Proyek Hibah Tim dan Program sandwich, serta ACIAR (Australian Centre for International Agricultural Reseach) atas dukungan dana untuk melakukan penelitian.

\section{DAFTAR PUSTAKA}

Akin, MH. And Sudarsono. 1997. Characterization of peanut stripe virus (PStV) isolated from various provinces in Indonesia. IJTA 8:13-20.

Fankel, M. J., C.W. Ward, and D.D. Shukla. 1989. The use of 3' non-coding nucleotide sequences in taxonomy of potyviruses: Application to watermelon mosaic virus 2 and soybean mosaic virus-N. J. Gen. Virol. 70:2775-2783.

Francki, R.I.B., C.M. Fauquet, D.L. Knudson, and F. Brown. 1991. Classification and nomenclature of viruses. Arch. Virol. 2:351-156.

Gunashinghe, U.B., S. Flasinski, R.S. Nelson, and B.G. Cassidy. 1994. Nucleotide sequence and genome organization of peanut stripe potyvirus. J. Gen. Virol. 75:2519-2526.

Lindbo, J.A., L Silva-Rosales, and W.G. Dougherty. 1992. Pathogen derive resistance to potyvirus: Working, but why?. Department of Microbiology, Oregon State University.

Shaw, J.G., A.G. Hunt, T.P. Pirone, and R.E. Rhoads. 1990. Organization and expression of potyvirus genes. In Pirone, T.P. and J.G. Shaw (eds.). Viral genes and Plant Pathogenesis. Springer-Verlag. New York. 215p.

Shukla, D.D., and C.W. Ward. 1988. Amino acid sequence homology of coat proteins as a basis for identification and classification of the potyvirus group. J. Gen. Virol. 69:2703-2710.

Thomson, D., and R.G. Dietzgen. 1995. Detection of DNA and RNA plant viruses by PCR and RT-PCR using a rapid virus release protocol without tissue homogenization, J. of Virol. Methods 54:85-95.

Thomson, K.G. 1997. A pararetrovirus and retrotransposon in pineapple. $\mathrm{PhD}$ thesis the University of Queensland.

Tomaru, K. 1994. On new rules for classification and nomenclature of plant viruses. Proc. of the seminar on Biotechnology for Agricultural viruses, Yogyakarta August, 15-16, 1994. p.64-71.

Ward, C.W. and D.D. Shukla. 1990. Taxonomy of potyvirus: Current problems and some solutions. Intervirology 32:269-296. 